\title{
Commentary: When does size matter?
}

\author{
Constantine L. Athanasuleas, MD, FACC
}

From the Division of Cardiothoracic Surgery, Department of Surgery, University of Alabama at Birmingham, Birmingham, Ala.

Disclosures: Author has nothing to disclose with regard to commercial support.

Received for publication Dec 14, 2018; accepted for publication Dec 17, 2018; available ahead of print Jan 23, 2019.

Address for reprints: Constantine L. Athanasuleas, MD, FACC, 1720 2nd Ave S, THT 720, Birmingham, AL 35294-00065 (E-mail: cathanasuleas@uab.edu).

J Thorac Cardiovasc Surg 2019;158:70-1

0022-5223/\$36.00

Copyright (c) 2018 by The American Association for Thoracic Surgery

https://doi.org/10.1016/j.jtcvs.2018.12.050

Forty years ago, Rahimtoola ${ }^{1}$ described patient-prosthetic mismatch (PPM) after surgical aortic valve replacement (AVR). We were taught that PPM is bad and must be avoided, because left ventricular mass regression is impaired, affecting survival, especially in younger patients. A new question is now before us. Should anxiety about PPM lead us to choose transcatheter AVR (TAVR) in preference to surgical AVR (SAVR)?

PPM is controversial. Medalion and colleagues ${ }^{2}$ followed up patients for 20 years. Survival was not adversely affected by moderate PPM. Howell and associates ${ }^{3}$ studied 1481 patients and found that severe PPM was predicted in $4 \%$ to $10 \%$ of patients but did not affect in-hospital or midterm survival. Koch and coworkers ${ }^{4}$ reported excellent quality of life improvement after SAVR, even with severe PPM. A study by Moon and associates ${ }^{5}$ of 1400 consecutive patients undergoing SAVR showed that PPM had a negative effect on survival in younger patients but not in older patients. Conversely, and most recently, Fallon and colleagues $^{6}$ examined data from 59,779 patients in the Society of Thoracic Surgeons database from 2004 to 2014 and reported in 2018 that any degree of PPM significantly decreased long-term survival and increased readmission rates for both heart failure and reoperation for AVR.

In this issue of the Journal, Maeda and colleagues ${ }^{7}$ advocate the use of preoperative multislice computed tomography to predict PPM after SAVR or TAVR. Maeda and colleagues ${ }^{7}$ report a propensity-matched retrospective analysis of 72 patients, focusing on the sinotubular junction. As expected, TAVR (with Sapien or Sapien XT; Edwards Lifesciences, Irvine, Calif) provided superior hemodynamics. A small sinotubular junction $(<22.5 \mathrm{~mm})$ was an independent predictor of PPM after SAVR $(59.7 \%$ in SAVR vs $2.9 \%$ in TAVR). A low PPM rate was unrelated to aortic root size in the TAVR group. The incidence of aortic regurgitation, however, including paravalvular leaks, was greater in TAVR than in SAVR (aortic regurgitation $\geq$ grade II, $44.1 \%$ vs $7.1 \%$ ), attributable to devices no longer in use. Maeda and colleagues ${ }^{7}$ conclude that TAVR is an option to prevent PPM, especially in patients with a small aortic

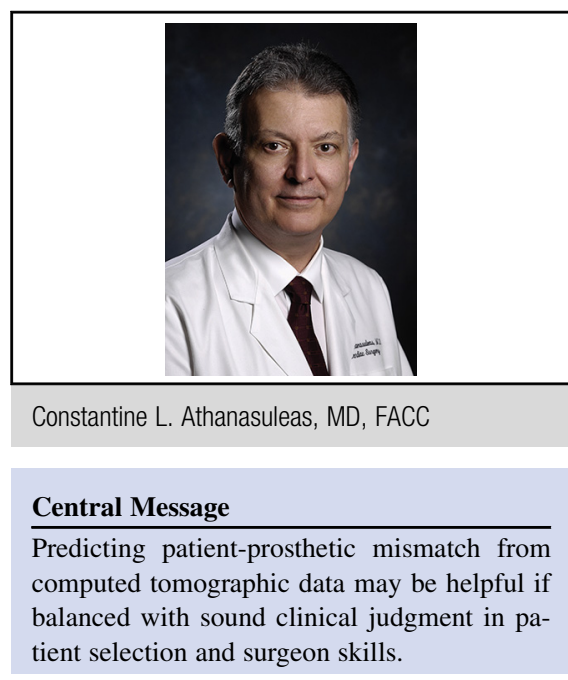

See Article page 61.

root. That said, the surgical group was small, and 5 different bioprostheses were used, with varied PPM incidence even among 19-mm devices. Perhaps the high rate of PPM in the SAVR group was related to the use of everting mattress sutures with pledgets in the supra-annular position, placing the valve in the annulus and resulting in smaller valve choices.

Ultimately, a prudent course is perhaps to evaluate the needs of the patient beyond a single measurement. Is the patient elderly and relatively immobile, or young and vigorous? Tailoring the operation to the needs of the patient and the operative risk should be the goal. The data of Maeda and colleagues ${ }^{7}$ undoubtedly are helpful but should be viewed in this context. If, for example a younger patient has a small sinotubular junction, the surgeon should consider the longevity of SAVR versus TAVR and their associated complications. If confident, the surgeon may choose root enlargement, which usually results in upsizing the prosthesis by 1 or 2 measures. We are in an era of boutique surgery.

\section{References}

1. Rahimtoola SH. The problem of valve prosthesis-patient mismatch. Circulation. 1978;58:20-4.

2. Medalion B, Blackstone EH, Lytle BW, White J, Arnold JH, Cosgrove DM. Aortic valve replacement: is valve size important? J Thorac Cardiovasc Surg. 2000;119: 963-74.

3. Howell NJ, Keogh BE, Barnet V, Bonser RS, Graham TR, Rooney SJ, et al. Patient-prosthesis mismatch does not affect survival following aortic valve replacement. Eur J Cardiothorac Surg. 2006;30:10-4.

4. Koch CG, Khandwala F, Estafanous FG, Loop FD, Blackstone EH. Impact of prosthesis-patient size on functional recovery after aortic valve replacement. Circulation. 2005;111:3221-9. 
5. Moon MR, Pasque MK, Munfakh NA, Melby SJ, Lawton JS, Moazami N, et al. Prosthesis-patient mismatch after aortic valve replacement: impact of age and body size on late survival. Ann Thorac Surg. 2006;81:481-8; discussion 489.

6. Fallon JM, DeSimone JP, Brennan JM, O'Brien S, Thibault DP, DiScipio AW, et al. The incidence and consequence of prosthesis-patient mismatch after surgical aortic valve replacement. Ann Thorac Surg. 2018, 106:14-22.

7. Maeda K, Kuratani T, Yoshioka D, Pak K, Shimamura K, Toda K, et al. Predicting patient-prosthetic mismatch by aortic root evaluation before aortic valve replacement. J Thorac Cardiovasc Surg. 2019;158:61-9.e4. 